\title{
A RE-LIGAÇÃO NA LICENCIATURA EM MATEMÁTICA: UMA VISÃO A PARTIR DO ESTÁGIO CURRICULAR
}

José Ivanildo de LIMA

Núcleo de Desenvolvimento da Pesquisa em Educação Matemática e Científica/UFPA

jivalima@yahoo.com.br

Isabel Cristina Rodrigues de LUCENA

Núcleo de Desenvolvimento da Pesquisa em

Educação Matemática e Científica/UFPA

ilucena@ufpa.br

Resumo: Este artigo é um recorte da pesquisa de mestrado, defendida em março de 2008, junto ao Programa de Pós-Graduação em Educação em Ciências e Matemáticas da Universidade Federal do Pará, cujo objeto de estudo é o estágio supervisionado na licenciatura em Matemática. Especificamente, tem o objetivo de descrever as possibilidades e limitações de constituição de práticas colaborativas no estágio curricular, motivadas por questões que dicotomizam a formação do futuro professor de matemática. Para tal, dispomos de entrevistas de três licenciandos e quatro professores de uma escola pública, para a obtenção dos dados aqui analisados. Os licenciandos faziam parte da disciplina Prática de Ensino/Estágio Supervisionado do curso de Licenciatura em Matemática da UFPA. A discussão mostra que os saberes da ação pedagógica, quando mobilizados no estágio curricular, podem ajudar na superação do problema da dicotomização na/da Licenciatura em Matemática, facilitando o desenvolvimento de práticas colaborativas e produção de saberes docentes.

Palavras-chave: Estágio. Práticas Colaborativas. Epistemologia da Prática.

Abstract: This article is a cutting of the Master's degree research, defended in March of 2008, the Program of Masters degree in Education in Sciences and Mathematics of the Federal University of Pará, whose study object is the apprenticeship supervised in the upbringing in Mathematics. Specifically, it has the objective of describing the possibilities and limitations of constitution of practical to help out in the apprenticeship curricular, motivated by subjects that dichotomizes the future mathematics teacher's formation. For such, we have interviews of three upbringing and four teachers of a public school, for the obtaining of the data here analyzed. The upbringing was part of the Practical discipline of Supervised Teaching/Traineeship 
of the course of Upbringing in Mathematics of UFPA. The discussion shows that know them of the pedagogic action, when mobilized in the apprenticeship curricular, they can help in the overcome of the problem of dichotomizes of Upbringing in Mathematics, facilitating the development of practical to help out and production of you know educational.

Keywords: Apprenticeship. Practical to Help out. Epistemology of the Practice.

\section{Introdução}

Inicialmente esclarecemos que este artigo é resultado da pesquisa de mestrado intitulada $\mathrm{O}$ estágio supervisionado na Licenciatura em Matemática: possibilidades de colaboração. A discussão aqui trazida emergiu da categoria de análise denominada Da dicotomização na/da licenciatura à re-ligação. Neste artigo consideramos apenas as entrevistas semi-estruturadas, realizadas com os licenciandos e professores-escolares e a imersão (observação e vivência) dos formadores (pesquisadores) no ambiente de estágio, tanto na escola-campo, quanto nas aulas dentro da UFPA.

Para compreender o quadro teórico que construímos, julgamos importante tecer apontamentos que fundamentam o nosso olhar sobre o estágio. Dessa forma, apresentamos os principais conceitos tratados no texto referentes aos saberes docentes e epistemologia da prática profissional, para em seguida, explicitar nossa concepção de estágio como pesquisa.

Após este quadro montado, serão esboçadas três dicotomias encontradas na categoria de análise descrita acima: a) disciplina específica/ disciplina pedagógica; b) professores de disciplinas específicas/professores de disciplinas pedagógica; e c) universidade/escola.

Finalizamos o artigo com ações e falas que demonstram possibilidades da re-ligação na Licenciatura em Matemática.

\section{Os saberes docentes no estágio}

Existe correntemente, nas licenciaturas em Matemática, a ideia de que o estágio curricular supervisionado é apenas o momento de "mandar" os licenciandos para a escola, sendo a hora de colocar em prática a teoria estudada nos cursos de formação. Percebemos ainda que, em 
alguns departamentos de matemática, o estágio é tratado sem qualquer reflexão mais aprofundada, sendo comum vermos a ênfase dada apenas a conhecimentos específicos da matemática, em detrimento das outras formas de saber.

Adotamos a denominação de Gauthier et al.(1998) e/ou Tardif (2002), sobre os saberes docentes, denominados como saberes:experienciais, disciplinares, da tradição pedagógica, das ciências da educação, curriculares e da ação pedagógica, por percebemos que nos modelos de estágio, são dadas ênfases sobre os saberes disciplinares, e quando muito, aos saberes experienciais dos professores da escola, ou ainda a imitação e reprodução dos saberes dos formadores da universidade.

\subsection{Em busca dos saberes da ação pedagógica}

Os saberes disciplinares, segundo Gauthier (1998, p. 29), são "os saberes produzidos pelos pesquisadores e cientistas nas diversas disciplinas científicas, ao conhecimento por eles produzidos a respeito do mundo". No contexto da Licenciatura em Matemática podemos compreendêlos como os saberes produzidos no próprio campo da Matemática, o conhecimento dos objetos matemáticos, teoremas e suas demonstrações, a manipulação desses objetos, os fundamentos epistemológicos da disciplina. Quando a formação do professor de matemática toma como ponto de partida e de chegada esses saberes, o futuro profissional acaba por desenvolver uma "visão internalista da própria matemática", como diz D’Ambrósio (1990). Dominar os saberes disciplinares não significa reduzir o ensino e aprendizagem de matemática à própria Matemática. Significa entender a existência dessa visão e equilibrar o quanto dela deve ser incorporada em atividades de ensino e aprendizagem.

É imprescindível ao futuro professor apreender o conteúdo da matemática, mas não necessariamente o é ao pesquisador matemático. Pela natureza da profissão deve ter acesso a outras formas de saberes indispensáveis à sua prática pedagógica. Podemos dizer que o objeto de trabalho do professor de matemática é diferente do objeto dos matemáticos (FIORENTINI; LORENZATO, 2006) e, portanto, a redução do ensino de matemática aos saberes disciplinares é, no mínimo, um complicador para a aprendizagem dos alunos. 
Já os saberes experienciais, para Tardif (2003, p. 43), são “o conjunto de saberes atualizados, adquiridos e necessários no âmbito da prática da profissão docente e que não provêm das instituições de formação nem dos currículos". Os professores de matemática acabam por adquirir ao longo dos anos, seu estilo de ensino, macetes, crenças que acabam por se apresentarem repetidas vezes ou de forma habitual. Como diz Gauthier et al. (1998, p. 33), o professor elabora "ao longo do tempo uma espécie de jurisprudência composta de truques, de estratagemas e de maneiras de fazer que, apesar de testadas, permanecem em segredo".

Gauthier (1998, p. 33) mostra-nos que o saber da ação pedagógica "é o saber experiencial dos professores a partir do momento em que se torna público e que é testado através das pesquisas em sala de aula”. Tanto o professor-escolar quanto o professor-formador, naturalmente detentores de saberes experienciais, por já possuírem uma prática docente, podem encontrar no estágio lugar para avançar até o compartilhamento de saberes validados por um grupo constituído de diferentes olhares e práticas, enriquecendo as experiências.

O próprio Gauthier (1998) nos chama atenção para o fato de que "os julgamentos dos professores e os motivos que lhes servem de apoio podem ser comparados, avaliados, pesados, a fim de estabelecer regras de ação que serão conhecidas e aprendidas por outros professores". Tanto a instituição formadora quanto a escola campo de estágio serão beneficiadas com as trocas resultantes da pesquisa no estágio. Assim como os saberes da ação pedagógica são legitimados por esse intercâmbio de saberes faz-se necessário entender o estágio como pesquisa.

\subsection{Estágio e pesquisa sobre a prática: a colaboração}

Pensar o Estágio Supervisionado a partir de um olhar científico não é mergulhar num cientificismo ${ }^{1}$, mas buscar uma aproximação das ideias de pensadores, pesquisadores e profissionais para agir dentro de situações refletidas. É tentar ultrapassar o paradigma atual de que o estágio serve apenas para testar a teoria estudada nos cursos de (in) formação.

\footnotetext{
${ }^{1}$ Aqui este termo tem o sentido de superar a concepção positivista da ciência, onde enaltece o estado positivo da filosofia comteana.
} 
Julgamos necessário começar lançando um olhar sobre a postura do professor-formador por ser um dos principais atores nesta pesquisa. Assim, a postura que propomos é de um profissional formador mobilizador de um conjunto de saberes específicos inerentes ao estágio. O estágio aqui é entendido como campo de conhecimento (PIMENTA; LIMA, 2004), constituindo-se em um componente curricular nos cursos de formação de professores de Matemática.

Essa ideia de estágio pode possibilitar aos envolvidos no processo - professor, licenciando e professor-escolar - a produção coletiva de saberes sobre o ensino e aprendizagem de Matemática, aproximandose de "uma epistemologia da prática docente, capaz de conferir estatuto próprio de conhecimento ao desenvolvimento dos saberes" (PIMENTA; LIMA, 2005, p. 49).

Acreditamos que o Estágio Supervisionado deva caminhar rumo a uma epistemologia da prática profissional que busque:

\section{[...] revelar esses saberes [OS SABERES DOCENTES], compreender como são integrados concretamente nas tarefas dos profissionais e como estes os incorporam, produzem, utilizam, aplicam e transformam em função dos limites e dos recursos inerentes à suas atividades de trabalho. Ela [EPISTEMOLOGIA DA PRÁTICA] também visa compreender a natureza desses saberes, assim como o papel que desempenham tanto no processo de trabalho docente quanto em relação à identidade profissional dos professores (TARDIF, 2002, p. 256).}

Com esta perspectiva de estágio voltada para a reflexão sobre esses aspectos epistemológicos relativos à natureza dos saberes e do papel do professor-formador no estágio supervisionado em Matemática, pode-se encontrar eco nas palavras de Gonçalves (2006) quando expõe sobre a formação e o desenvolvimento profissional de formadores de professores de matemática na Universidade Federal do Pará:

A reflexão/análise proporcionada pela pesquisa leva os formadores a transformar suas práticas e teorias implícitas (crenças, concepções e idéias sobre conhecimento, ensino, aprendizagem...), a desenvolver o pensamento críticoreflexivo, a 'resignificar' conhecimentos já adquiridos e

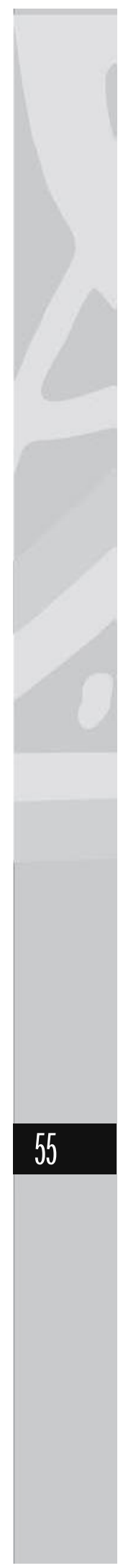


a produzir novos conhecimentos profissionais. Tudo isso contribui para a construção da identidade profissional do professor, de sua autonomia intelectual, promovendo, desta forma, o desenvolvimento profissional do formador (GONÇALVES, 2006, p. 36).

Entender o estágio como campo de conhecimento é justamente buscar essa re-significação de conhecimentos já adquiridos e produzir novos, dando oportunidade de se desenvolver um pensamento crítico-reflexivo, proporcionando a sua autonomia intelectual.

Proporcionar autonomia intelectual para futuros professores significa incorporarmos o estágio como pesquisa, pois nele existe um lugar privilegiado à criação de um ambiente no qual os saberes da ação pedagógica sejam permanentemente discutidos num coletivo. Nesse ambiente, esses saberes são públicos, prudentes e críticos, produzidos e validados coletivamente no ambiente real do trabalho docente (GALTHIER et al., 1998; GONÇALVES, 2000; GONÇALVES, 2006). Dessa forma, estamos compactuando com a ideia de que:

É preciso que os professores orientadores de estágios procedam, no coletivo, junto a seus pares e alunos, a essa apropriação da realidade, para analisá-la e questioná-la criticamente à luz de teorias. Essa caminhada conceitual certamente será uma trilha para a proposição de novas experiências. (PIMENTA, 2004, p. 45).

Então, novas experiências realizadas a partir da postura do professor-formador, do licenciando e do professor-escolar, como pesquisadores de suas próprias práticas docentes e responsáveis pela produção de um conjunto de saberes da experiência, poderão, mais tarde, se constituir em saberes da ação pedagógica tornando-se público ${ }^{2}$ e testado através das pesquisas realizadas em sala de aula (GAUTHIER et al., 1998, p.33).

${ }^{2}$ Os Saberes Públicos são os saberes oriundos das ciências da educação, dos conhecimentos disciplinares e das teorias. O Saber Privado é o saber da experiência, construído na prática pelos docentes no exercício profissional e que não chega a ser socializado e validado pelo coletivo dos professores. É um saber que por se originar do convívio diário na sala de aula, sofre restrições, principalmente nos meios acadêmicos (GONÇALVES, 2006). 
Com este pensar, fica claro que devemos sair do ponto em que cada professor, sozinho em seu próprio universo, elabora uma espécie de jurisprudência particular feita de mil e um truques que "funcionam" ou acredita funcionarem (GAUTHIER et al., 1998, p. 34), fortalecendo substancialmente alguns mitos sobre o ofício do professor. Esse fato, dentro da cultura docente e do imaginário daqueles que se aventuram ser professores de matemática, se traduz pela ideia corrente de que para ser professor da área basta apenas dominar os "macetes" relativos ao conteúdo específico, ou seja, Matemática. Basta saber os atalhos de como manipular bem as propriedades, os conceitos e definições, fazer algumas demonstrações clássicas - e pronto!

Compreendemos então que um novo paradigma se faz presente para que o estágio curricular em matemática dê lugar à pesquisa. Esta poderá redimensionar a prática e as teorias do docente, revitalizando e reproduzindo os saberes da ação pedagógica (GONÇALVES, 2006, p. 56), valorizando outros saberes, principalmente aqueles validados e discutidos pelos professores e futuros professores num coletivo, sejam eles da universidade ou da escola.

\section{A re-ligação na Licenciatura em Matemática: necessidade de práticas colaborativas}

Nos últimos anos, a licenciatura em matemática tem sido foco de discussão e pesquisas, as quais fundamentalmente apontam críticas severas ao modelo denominado " $3+1$ ", cuja ideia central é a formação do professor baseada nos três anos iniciais, no estudo de disciplinas específicas, somados a um ano de disciplinas ditas pedagógicas. É recorrente o apelo de professores e pesquisadores sobre o problema da dicotomização da teoria com a prática, o que acima já foi discutido com olhar no estágio, baseado nos trabalhos de Pimenta e Lima (2004).

Em nossa pesquisa, percebemos que, além deste problema, o estágio curricular na UFPA (pelo menos no Campus José Silveira Netto) enfrenta outras formas de dicotomização que são limitadores na efetivação de práticas colaborativas dentro do estágio curricular em Matemática. Primeiro, destacamos a relação teoria-prática vinculada a um problema curricular na licenciatura. Depois, visualizamos a ampliação da dicotomia existente nessa relação, no ideário do professor-formador e no agravo do

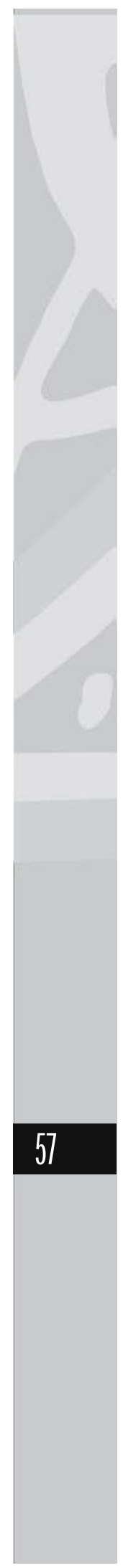


distanciamento físico entre as instituições responsáveis pela formação de um mesmo professor e da dicotomia mal resolvida entre universidade e escola, ambiente do estágio.

\subsection{Dicotomia: disciplina específica e disciplina pedagógica}

A matriz curricular das licenciaturas em Matemática, em particular, da UFPA - Campus José Silveira Netto - anterior a proposta do Projeto Pedagógico atualmente em vigor $^{3}$, ainda configura distanciamentos entre disciplinas específicas e/ou pedagógicas. A busca por um ponto de equilíbrio entre as diversas formas de saberes que constituem não só as disciplinas do curso como também a formação docente, em geral, fica reduzida ao saber da matéria, isto é, ao saber disciplinar.

Por si só, essa compreensão da matriz curricular é prejudicial à formação e ao desenvolvimento profissional do futuro professor, pois, ela é dicotomizante. Essa maneira de dicotomizar na formação do professor já foi de alguma forma - e em outro contexto - discutida por Gonçalves (2001). Gonçalves indica questões sobre esse problema em sua tese de doutoramento envolvendo oito formadores de professores do Departamento de Matemática (atual Faculdade de Matemática da UFPA), revelando que a formação matemática do professor precisa de reflexão e de aproximação de todos os envolvidos no processo. Em suas reflexões, mostra que a matriz curricular dos cursos de matemática, não só da UFPA, como da maioria das universidades públicas, é composta de conteúdos suficientes para formar professores de Matemática qualificados (GONÇALVES, 2006).

Esta problemática é trazida à tona em nossa pesquisa quando ocorre a imersão do licenciando, no momento de estágio, pois aqui fica fortemente evidenciado que:

A universidade tem deixado muito a desejar com relação à preparação do futuro docente. Infelizmente a maioria dos nossos professores [formadores] estava reduzindo as matérias pedagógicas, como se elas não fossem importantes. Se o

${ }^{3}$ Atualmente encontra-se em vigor e já em fase de reformulação o Projeto Pedagógico elaborado em 2004/UFPA/Campus José Silveira Netto. 
'cara' não é bem preparado aqui na universidade como é que ele vai ser um bom professor em termos didáticos lá na escola? (PAULO - licenciando em matemática em 2006, entrevista).

O licenciando Paulo, durante sua formação, percebeu uma espécie de menosprezo às disciplinas pedagógicas por parte de alguns formadores da universidade que não vêem o crédito pertinente a uma possível integração entre as formas de saberes.

Nossa visão sobre este problema da dicotomização da matriz curricular do curso está relacionada à compreensão de uma epistemologia da prática profissional por parte do professor-formador, o qual não visualiza o conjunto de saberes utilizados realmente por eles em seu espaço de trabalho cotidiano para desempenhar suas próprias atividades de formador (TARDIF, 2003), reduzindo sua própria prática simplesmente a ministração do conhecimento matemático.

Fica evidente, portanto, que a dicotomização discutida aqui tem grande influência na concepção de estágio tanto quanto nas posturas, práticas e crenças dos futuros professores. O próprio licenciando percebe essa separação e o possível prejuízo decorrente dela à sua formação, pois ele mesmo relata que "alguns [formadores] acham que só aprender o conteúdo é importante; e não é isso, a gente tem que ter a prática em parceria com a teoria, não só nas matérias pedagógicas, mas também nas de matemática pura" (Paulo - licenciando em 2006, entrevista).

Moreira e David (2007, p. 15), discutem esse assunto justificando que:

O saber docente é decomposto em componentes, de tal forma que um deles, o chamado conhecimento da disciplina, assume a condição essencial. Os demais conhecimentos, ainda que reconhecidos como saberes complexos e importantes, conformam um conjunto de conhecimentos de caráter basicamente acessório ao processo de transmissão do saber disciplinar.

A nossa busca está baseada na superação de práticas e posturas dessa natureza, em relação à ideia que é construída sobre a matriz curricular, pois vemos que quando estamos imersos num coletivo de profissionais, cada qual busca expor seu olhar e ao mesmo tempo respeitar o olhar do 
outro. Encontrar o equilíbrio discutido por Gonçalves (2006) diante desse problema, em nossas análises, requer a implementação de práticas colaborativas no estágio curricular, pois, nessa perspectiva, o diálogo e o suporte entre os envolvidos oportunizariam a produção de saberes da ação pedagógica. Dessa forma seria possível, aos colaboradores, compartilhar seus saberes experienciais em buscas de equilíbrios no que diz respeito à validação entre ideias e práticas.

Por isso visualizamos que este problema vai além da relação teoriaprática, como expressa Gonçalves (2006, p. 28), quando se coloca:

Plenamente de acordo com a necessidade posta de uma boa formação pedagógica acompanhada de uma boa formação matemática, assinalando como atributo de qualidade que estas duas vertentes sejam trabalhadas de forma conjunta - ou termos consoantes - pelo formador de professores das disciplinas específicas.

Diante do exposto, pensamos que superar esta forma de dicotomização, implica num avanço na formação e no desenvolvimento profissional do futuro professor de Matemática da UFPA, no momento de estágio.

\subsection{Dicotomia: professores de disciplinas específicas e das} disciplinas pedagógicas

Parece-nos que a separação entre as disciplinas de conteúdos "específicos" e "pedagógicos", moldada pela epistemologia do professor e, por conseguinte, pela sua prática, amplia-se para a constituição de grupos com características balcanizadoras. Não estamos advogando contra o fortalecimento de grupos de estudos e pesquisas com área de concentração e linhas de pesquisa bem definidas. Porém, chamamos a atenção para o fato de que muitos professores de matemática, além de serem pesquisadores da área, são também formadores no curso de licenciatura e que, para esta função, é exigido pelo menos compreensão sobre os problemas da formação do futuro professor de matemática.

Nossa preocupação resulta da análise das falas dos colaboradores que implicitamente, denuncia uma cultura institucionalizada de grupos 
balcanizados. Podemos entender isto quando escutamos o depoimento de Paulo:

O interessante também é que dá pra observar que existe uma divisão aqui, entre a área pedagógica, da educação e da matemática pura, parece que o pessoal não se dão. Seria muito interessante que houvesse uma conexão. Isso daria uma grande contribuição para a parte didática dos futuros docentes. (PAULO - licenciando em matemática em 2006, entrevista - grifo nosso).

A ampliação do problema curricular para um nível que diz respeito à constituição de grupos balcanizados fica num nível de cooperação entre os responsáveis pela formação do professor. Isso implica em cumprimento de formalidades no sentido de execução de tarefas que envolvam as instituições formadoras. É interessante expor que pelo menos três Unidades Acadêmicas da UFPA - Campus José Silveira Netto - atuam simultaneamente nessa formação $\left(\mathrm{ICEN}^{4}, \mathrm{IEMCI}^{5}\right.$ e ICED $\left.{ }^{6}\right)$. É justamente o fechamento desta tríade de Unidades em seus espaços físicos, separados pela infra-estrutura da Universidade que incomoda o licenciando. A conexão defendida pelo futuro professor, entre as áreas de domínio de pelo menos essas três Unidades, pode ser timidamente identificada por conta de iniciativas isoladas entre poucos docentes.

Fullan e Hargreaves (2000), quando tratam do problema do individualismo institucionalizado, nos lembram "que prédios separados, salas de aula isoladas e recursos também individualizados são todas as características arquitetônicas capazes de induzir ao individualismo e dificultar o trabalho conjunto dos professores".

Neste caso, a individualização dicotomiza não apenas as atividades dos professores (pesquisador e docente), mas, também, as entidades que vem trabalhando na formação do mesmo licenciando, causando impactos profundos nas concepções, crenças e posturas e nas práticas. A balcanização também pode desencadear pequenas ilhas

\footnotetext{
${ }^{4}$ Instituto de Ciências Exatas e Naturais.

${ }^{5}$ Instituto de Educação Matemática e Científica.

${ }^{6}$ Instituto de Ciências da Educação.
} 
de conhecimentos desconectadas de outras e, ao invés promover a complementariedade entre elas, acaba por provocar competições e distanciamentos (Álgebra X Geometria, Etnomatemática X Didática da Matemática, entre outras).

Todo esse contexto constitui tanto a identidade do licenciando quanto a concepção de estágio dentro da licenciatura, induzindo a construção de saberes da tradição pedagógica (TARDIF, 2002; GAUTHIER, et al., 1998) negativos ao processo de formação e ao desenvolvimento profissional do futuro professor, pois estes saberes estão fundamentados na representação que se faz da profissão, mesmo antes de atuar, configurando sua maneira de lecionar.

Essa concepção de estágio é relatada por um dos colaboradores:

Eu acho que poucos colegas se envolveram no estágio. Eles já vêm com aquele pressuposto de que o estágio não serve pra nada, é isso que vinha acontecendo ao longo dos anos na Licenciatura em Matemática. [...] Eu via muito aqui os alunos dizerem que essas matérias da Educaşão não servem pra nada (JOAQUIM - licenciando em 2006, entrevista).

É urgente a superação deste problema. A constituição de grupos colaborativos pode ser uma alternativa à superação desse tipo de situação na Licenciatura, que em última instância corre o risco de desencadear um problema ético.

Mas é sabido que a própria forma como o curso foi instituído, ao longo dos anos, contribuiu para esse insinuante problema. Em Gonçalves (2006), é possível constatar a ideia de que a formação de professores de matemática na UFPA (e em vários estados brasileiros) foi construída encima do paradigma da racionalidade técnica, o qual não somente separa teoria da prática, mas também os formadores entre si e as Unidades Acadêmicas de uma mesma universidade.

É notório que começar a cursar as disciplinas pedagógicas somente a partir do $4^{\circ}$ semestre letivo, reforça a dicotomia que desde o início foi problematizada em nossa pesquisa. Insistimos nesse ponto porque os licenciandos, colaboradores do nosso estudo, enfatizaram a fragilidade do modelo " $3+1$ " que ainda é vigente em muitos cursos de licenciatura em matemática em nosso país. 
Ressaltamos que isso ocorreu porque os licenciandos foram remanescentes do Projeto Pedagógico antigo, elaborado antes de 2004, como bem expõe a licencianda:

A implementação de estágios no último semestre ainda é muito deficiente, passamos três anos e meio dentro de uma sala de aula aprendendo cálculos, álgebra, e até as disciplinas pedagógicas que eram para fazer o link das teorias com prática (seria a vivência das teorias psicológicas e filosóficas) não nos dão a verdadeira realidade da nossa profissão. Creio que pela vivência aprendemos mais do que pelos livros, pois é por ela que estamos em contato direto com as pessoas. (APARECIDA - licencianda, 2006, relatório).

Finalizamos esta seção apenas reafirmando a problemática discutida como dicotomizante e contrária ao desenvolvimento de práticas colaborativas no estágio.

\subsection{Dicotomia: universidade e escola}

Além do exposto acima, pudemos perceber que existe ainda outra dicotomização que deve ser considerada: aquela que separa a universidade da escola e vice-versa. Começaremos por analisar a seguinte fala:

Lá dentro, eles [professor-escolar] olhavam a universidade como um lugar distante... com os seus princípios, com sua doutrina, mas que aqui [escola] não vale... Aquilo não funciona aqui... Se algo que tenha lá for interessante pra gente, se couber, se der pra gente dar um jeitinho, pra ficar "bonitinho", então a gente pega, a gente usa, se não atrapalhar muito... Mas se "doer" um pouco, parou... Eu acho que não deveria ser assim. Acho que tudo que venha da universidade deve ser valorizado, buscado e ser recebido de braços abertos, ou que pelo menos tivesse uma análise. Mas que não tenha esse preconceito com as coisas que venham daqui... (JOAQUIM, Entrevista).

A relação universidade-escola é de extrema importância para o estágio supervisionado, porque é na escola que ele se dá. O estágio, como o discutido aqui, com base na tríade professor-escolar, licenciando 
e professor-formador e amparado em práticas colaborativas, poderá desenvolver-se qualitativamente para além do quadro teórico discutido acima, a partir da auto-percepção dos envolvidos como responsáveis por problematizarem as práticas da escola e da universidade, recriando um espaço de trocas mútuas.

O licenciando expressa o desejo da valorização do saber acadêmicocientífico pelo ambiente escolar e, concomitantemente, acrescentaremos que o movimento deve ser de mão dupla, ou seja, valorizar e respeitar os saberes da prática que são mobilizados na escola também são desejáveis para a formação durante o estágio. Talvez, aqui esteja boa opção para a utilização das pesquisas sobre ensino e aprendizagem da matemática (em todos os níveis e modalidades), que se amontoam nas bibliotecas das universidades, mas que não se materializam em mudança e inovação para a educação matemática.

Mas, na fala acima, ficamos preocupados com a visão do licenciando sobre a valorização somente do que é produzido na universidade, sem talvez compreender que a escola também é produtora de saberes. Por isso, perguntamos ao licenciando sobre a possibilidade da situação inversa, ou seja, como aquilo que vem da escola é visto dentro da universidade. Este se expressou dizendo:

Nunca parei pra pensar nisso profundamente, ou não tenho tantos argumentos. Mas vejo que existe sim, da universidade, certo preconceito contra aqueles conhecimentos que venham da prática. Já que se supõe que aqueles professores não pesquisam, não se renovam [...] já acham que toda aquela experiência não vale... (JOAQUIM, Entrevista).

A percepção do licenciando é de que a universidade seja um local tendencioso a não validar os saberes constituídos na escola. Daí é que vemos a importância da discussão do estágio como campo de conhecimento, propício para a produção de conhecimento dentro de um coletivo, porque a questão da validação dos saberes pode ser superada, diante do desenvolvimento dos saberes da ação pedagógica, mostrando-se capaz de conferir crédito nos espaços de formação, abandonando a condição de saberes experienciais num contexto privado e passando a ser públicos, nos quais escola e universidade, conjuntamente, trabalharão na sua produção e sistematização (GAUTHIER, et al.,1998). 


\section{Evidências das possibilidades de re-ligação na licenciatura}

Ao longo deste artigo temos procurado questionar e problematizar as dicotomias encontradas no momento do estágio supervisionado de Matemática. Também temos sustentado algumas possibilidades de desenvolvimento de práticas colaborativas como forma de re-ligação na licenciatura, enfatizando os saberes da ação pedagógica. Destacaremos a seguir ações e falas que se configuram como possibilidades de re-ligação, superando as limitações descritas acima.

A iniciativa de uma equipe de professores do antigo $\mathrm{NPADC}^{7}$, do Departamento de Matemática do $\mathrm{CEN}^{8}$, e de um mestrando do Programa de Pós-graduação em Educação em Ciências e Matemáticas ${ }^{9}$ para a elaboração do Projeto Integrado de Estágio, para o curso de matemática em 2005/2006, demonstra sementes de um trabalho colaborativo entre Unidades. O objetivo geral da referida proposta é desenvolver o Estágio Supervisionado - prevendo a integração entre as disciplinas Estágio I, II, III e IV (PP de Matemática, 2004) - à luz das exigências postas pela atual sociedade ao professor de matemática, numa perspectiva crítica e reflexiva, em ambientes e situações diversificadas.

Pudemos também vivenciar, nesta pesquisa, as expectativas do licenciando e do professor-escolar para um trabalho efetivo no ensino de matemática que considerasse os saberes disciplinares e outras formas de saberes:

Eles tinham um projeto [atividades pré-organizadas para execução no estágio], só que, infelizmente, pelo nosso planejamento ter um conteúdo muito vasto, não foi possivel que a gente desse huz a imaginação para desenvolver esse projeto. Eu achei muito interessante porque é uma contribuição, tanto institucional da UFPA com [a escola], quanto individual e profissional do acadêmico que está se

\footnotetext{
${ }^{7}$ Núcleo de Pesquisa e Desenvolvimento da Educação Matemática e Científica, atual Instituto de Educação Matemática e Científica.

${ }^{8}$ Atual Faculdade de Matemática do Instituto de Ciências Exatas e Naturais

${ }^{9}$ Nós, respectivos autores deste artigo, fazíamos parte dessa equipe também por interesses de pesquisa, tomando o estágio como objeto de estudo tanto na condição de professora do curso de mestrado do PPGECM (Isabel Lucena) e como orientando do referido curso (José Ivanildo Lima).
}

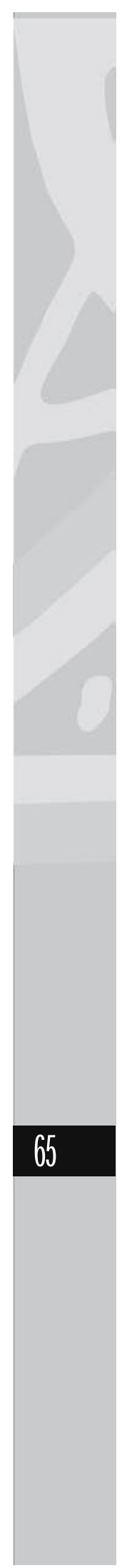




\begin{abstract}
formando, para com o professor e os alunos que estão aqui; porque é uma parte do tempo que a gente economiza deveria desenvolver outra tarefa de cunho educativo para os alunos, os próprios acadêmicos desenvolvem. (RODRIGO - professor escolar, 2006, entrevista).
\end{abstract}

Mesmosem a realização do projeto ${ }^{10}$ deste licenciando, foi propiciada a comunicação e diálogo entre os envolvidos no processo de estágio. A tríade professor-escolar, licenciando e professor-formador buscou discutir sobre a possibilidade da implementação do projeto na turma deste professor. Como ele mesmo disse, o planejamento e o conteúdo vasto impossibilitaram a realização das atividades propostas naquele projeto e que os próprios acadêmicos poderiam desenvolver essas atividades. Pensar os problemas da escola e as atividades conjuntamente, criticandoas e acrescentando outras, seria um exemplo de prática colaborativa que poderia estar, ao mesmo tempo, re-ligando todas as disciplinas estudadas no curso como, também, fortalecendo a relação escola-universidade.

Esse sentimento fica claro quando Joaquim relata:

Seria válido outra alternativa tipo colocar o licenciando pra dar aula, não de qualquer maneira, mas com toda uma orientação da equipe. (JOAQUIM, Entrevista - grifo nosso).

O licenciando também busca a re-ligação focada no senso de equipe, cuja orientação se revela pela participação de todos, professorformador, professor-escolar, colegas licenciandos, os quais possam discutir as atividades colaborativamente, fazendo aulas diferenciadas, e considerando as pesquisas da área de educação matemática.

Tais possibilidades devem ser ampliadas dando ao estágio curricular sua real contribuição na formação e no desenvolvimento profissional dos futuros professores de matemática.

\footnotetext{
${ }^{10}$ Projeto de ensino e aprendizagem elaborado durante a disciplina Prática de Ensino/ Estágio supervisionado (120h), durante as aulas na UFPA, antes da apresentação dos licenciandos nas escolas campo de estágio.
} 


\section{Considerações finais}

O estágio, a partir da perspectiva descrita aqui, buscou contemplar possibilidades de produção e sistematização de conhecimentos, dando ênfase a um movimento catalisador de sentido à produção tanto na escola, quanto na universidade, requerendo a criação e recriação dos saberes experienciais, mas almejando adentrar num coletivo de profissionais que discutam os problemas conjuntamente. Assim, é possível a criação da institucionalização de práticas, atitudes, crenças que possibilitem ao conjunto dos que realizam o estágio a compreensão dos os saberes da ação pedagógica (GAUTHIER, 1998).

Entretanto, questões estruturais devem ser superadas e também colocadas na mira dos objetivos principais de todos os segmentos envolvidos na formação do futuro professor de matemática e também na melhoria e democratização do ensino e aprendizagem nas escolas públicas. Portanto, a questão encontrada nesta pesquisa sobre a dicotomização na licenciatura, nas dimensões discutidas aqui, precisa ser superada e repensada com clareza e levadas para um espaço onde possamos negociar novas metas e objetivos comuns.

As possibilidades de se desenvolver práticas colaborativas, conforme interpretamos, sugerem a geração de ações de qualidade na formação e no desenvolvimento profissional dos professores que ensinam matemática. Entretanto, o estágio, tanto dentro da instituição formadora quanto da escola-campo, deve superar a dicotomia disciplina específica/disciplina pedagógica que se traduz pela ideia da verificação do conteúdo matemático dos licenciandos e pela forma de abordagem dos saberes disciplinares, pois este fato tem resultado na formação de um futuro professor conteudista, com visão puramente internalista (D’AMBRÓSIO, 1990).

Como vimos, o efeito dessa dicotomia se amplia até o ideário dos formadores, gerando um obstáculo que interfere no sucesso da formação de grupos com práticas colaborativas. Pensar o estágio com práticas colaborativas e como produtor de saberes da ação pedagógica é caminhar rumo à re-ligação da licenciatura, podendo esta, aproximar a universidade da escola e a escola da universidade. 
D’AMBRÓSIO, U. Etnomatemática. São Paulo: Ática, 1990.

FERREIRA, A. C. O trabalho colaborativo como ferramenta e contexto para o desenvolvimento profissional: compartilhando experiências. In: NACARATO, A. M.; PAIVA, M. A. V. (Orgs.). A Formação do Professor que Ensina Matemática: perspectivas e pesquisas. Belo Horizonte: Autêntica, 2006.

FIORENTINI, D. (Org.). Formação de Professores de Matemática: explorando novos caminhos com novos olhares. Campinas: Mercado de Letras, 2003.

. Pesquisar práticas colaborativas ou pesquisar colaborativamente? In: BORBA, M. de C.; ARAÚJO, J. de L. (Orgs.). Pesquisa Qualitativa em Educação Matemática. Belo Horizonte: Autêntica, 2004.

FULLAN, M.; HARGREAVES, A. A Escola como Organização Apreendente: buscando uma educação de qualidade. 2. ${ }^{a}$ Ed. Porto Alegre: Artmed, 2000.

GAlThIER, C. et al.. Por uma Teoria da Pedagogia: pesquisas contemporâneas sobre o saber docente. Ijuí: UNIJUI, 1998.

GONÇALVES, T. O. Formação e Desenvolvimento Profissional de Formadores de Professores: o caso dos professores de matemática da UFPA. Tese de Doutoramento. Campinas: Unicamp, 2000.

.AConstituição do Formador de Professores de Matemática: a prática formadora. Belém: CEJUP Editora, 2006.

LIMA, J. I. O Estágio Supervionado na Licenciatura em Matemática: possibilidades de colaboração. Dissertação de Mestrado. Belém: NPADC/UFPA, 2008.

LIMA, M. S. L. A Hora da Prática: reflexões sobre o estágio supervisionado e a ação docente. 4. ${ }^{a}$ ed. Fortaleza: Demócrito Rocha, 2004.

MOREIRA, P. C.; DAVID, M. M. A Formação Matemática do Professor: licenciatura e prática docente escolar. Belo Horizonte: Autentica, 2007.

PIMENTA, S. G.; LIMA, M. S. L. Estágio e Docência. São Paulo: Cortez, 2004.

TARDIF, M. Saberes Docentes e Formação Profissional. Petrópolis: Vozes, 2002. 